\title{
English as a Lingua Franca in a Multilingual India
}

\author{
Ishwarya N. Iyer \\ Indiana University \\ Correspondence concerning this review article should be addressed to Sridhar Ramachandran, Indiana \\ University Bloomington, 107 S Indiana Ave, Bloomington, IN 47405, USA. E-mail: iniyer@iu.edu

\section{Sridhar Ramachandran} \\ Indiana University

\begin{abstract}
Correspondence concerning this review article should be addressed to Sridhar Ramachandran, Indiana University Southeast, 4201 Grant Line Rd. New Albany, IN 47150, USA.E-mail: sriramac@ius.edu
\end{abstract}

\begin{abstract}
In this opinion article, we highlight that the cultural policy of language in India has resulted in an impasse in regard to determining and deciding upon a national language policy. We then summarize how English use across India has been elevated to the status of a lingua franca (amidst the language policy impasse), making it an indispensable part of the system and the economy. In that context, this opinion article presents the various tenets of the language policy issue with recommendations for educators in India on how to utilize best practices from literacy, culture, and language education (LCLE) literature to improve and maintain the quality of education whilst operating within the confines of the language policy impasse.
\end{abstract}

Keywords: cultural literacy, cultural politics of language in India, language policy, linguicism, multilingual India

Language policy is and has been one of the most deliberated issues in India (Bhattacharya, 2017). India is a democratic, multilingual, omnistic, multiethnic, and a multicultural country, and so a perplexing and nagging issue bothering Indian educators and education policy makers is arriving at the decision on what basal language to settle on (amicably) as the elemental medium of pedagogy within the public school system (Shin, 2013). The complexity of the issue can be realized from the notes taken (quoted below) by Dr. Ambedkar, who chaired the committee that drafted the constitution of the country following the country's independence from the British colonists in 1947. The notes quoted below are from the session when a single national language was being considered.

“...There was no article which proved more controversial than Article 115 which deals with the question. No article produced more opposition. No article more heat. After a prolonged discussion when the question was put, the vote was 78 against 78 . The tie could not be resolved. After a long time when the question was put to the party meeting the result was 77 against 78 for Hindi. Hindi won its place as a national language by one vote. I am stating these facts from my personal knowledge." (Ambedkar, 2014, p. 148)

Logic would suggest that the national language would be the natural choice as the primary medium of instruction in the country's public school system. However, that was not to be the case.

India consists of 29 states (and 7 union territories) with each state having its own linguistic identity ${ }^{1}$. Naturally, the political priority (and need) for each state was to safeguard and develop its own regional language and thus its cultural literacy. Thence, national language planning suffered because the "linguistic consciousness and

\footnotetext{
${ }^{1}$ Source: National Portal of India: https://india.gov.in/ (Accessed on November, 1, 2017)
} 
ethno-nationality on a territorial basis" resulted in an immediate "erosion of a national consensus for Hindi" (Dua, 1993, p.295). So, while 'Hindi' was posited as the national language of India on the policy document, it was undermined by a work-around that allowed for the continued use of English until a consensus was reached on Hindi (or any other language) as its replacement (Shin, 2013). No specific date (or deadline) was set for this replacement to take effect, and so the use of English in India prevailed (Dua, 1993).

It is also worth noting that the various commissions and committees appointed over the years by the Government of India could not agree on a language policy to be enforced across the public schools of India (Bhattacharya, 2017). The first such committee (called the Tara-Chand committee) that convened in 1948, 'suggested replacing English in educational institutions with the local language instead' (Dua, 1993). However, the University Education Commission's (UEC) Report of 1949 advocated the need for high school graduates and university graduates to be familiar with at least three languages - the local language, the national language, and English (Devi, 2017). The need for the knowledge of English for graduating students stemmed from the need to grant them access to a wider pool of literature written in English, thus helping them go beyond the local literature that was only available in the local language. Thereafter, in 1953, the Secondary Education Commission expanded upon the UEC Report of 1949 by adding a fourth language requirement called the 'classical language' requirement. This referred to the ancient languages of India that had a rich literature repository (Jayalakshmi \& Kothari, 2017). In 1956, the Central Advisory Board of Education (CABE) offered a language formula called the "Three Language Formula" (TLF) (Dua, 1993, p.303). According to the TLF, a student would study three languages, i.e. - the state's language, Hindi in states or regions that do not use Hindi or a non-Hindi language where Hindi is the local language, and English or a comparable world/modern language (Shin, 2013). The TLF was further refined by the Education Commission in 1966 and the modified TLF (mTLF) recommended that the three languages be - the state's language or the native language of the learner, Hindi or English, and a modern/ classical Indian language or a comparable world/modern language (Devi, 2017). As a result, English continued to find a unique and indispensable position of status in the Indian K-12 system and beyond.

\section{The Three Language Formula}

The mTLF was not an offical policy and emerged as a strategy out of a political reconciliation on language use for pedagogy across schools in India (Pattanayak, 1990). It gained popularity amongst educators and is the one currently used across India because it supports the common consensus that an Indian would need to be multilingual in order to communicate, interact, socialize, and conduct business with fellow citizens belonging to different regions of the country (Devi, 2017). According to the MTLF, the three recommended language learning options are (ref: Kochhar, 2000):

- The state's language (e.g. The state language is 'Tamil' in the state Tamilnadu) or the native language of the learner (e.g. 'Punjabi' language when the learner is from the Punjab state and speaks Punjabi at home but the learner is now settled in Tamilnadu) (L1);

- India's official languages (Hindi or English) since the national language is 'Hindi' but the use of English is officially allowed until a consensus is reached on the national language's status (L2);

- A modern/classical Indian language or a comparable world/modern language (L3).

The First Language (L1): The aim of the MTLF was to encourage the use of the mother/native tongue language as a medium of instruction in at least the elementary school grade levels with the aim to idealistically continue its use from K-12 and beyond (Devi, 2017).

The Second Language (L2): The second language is recommended to be introduced after the learner has already demonstrated some mastery over the first language (at the start of middle school onwards). The aim of the L2 was to help the learner associate and understand one of the official languages of the country as they prepare to become productive future citizens (Pattanayak, 1990).

The Third Language (L3): The third language is encouraged to be introduced at a later stage in the child's education (preferably at the end of the middle school) with the aim of providing the learner with an additional language to expand their learning experience and communication opportunities (Dua, 1993).

Thus, in spirit, the mTLF allows for a student from a Hindi speaking region to be able to learn the English 
language and a non-Hindi Indian language while a student from a non-Hindi speaking region to be able to learn the English language and the Hindi language (Devi, 2017). Hence, the appeal of the mTLF strategy was that it encouraged the multilingualism that is representative of the true quality of India. Also, a crucial element of the formula is that it seeks to "promote languages of wider communication at three different levels: regional, national and international” (Orman, 2008, p.57).

Since the mTLf is a strategy and not a policy, it has been open to interpretation and so has been adapted differently across the various Indian states and school systems. While some states accepted the mTLF in principle, others made some adjustments and changed it to match their social, cultural, and political needs. For example, the southern states did not want to teach Hindi to their learners and several northern Hindi speaking regions never included any south Indian language into their school syllabus (Annamalai, 2004). This meant that the only common language implemented across all the states in India was English since it remained uncontested and universally accepted. So, the language which was initially accepted and allowed as a medium of instruction at the higher education system level in a very limited scope was now being used not only as a medium of instruction in the grade schools but also for official and unofficial communication and correspondence between states, thus unifying people and establishments all across the country (Omidvar \& Ravindranath, 2017). This functional expansion of the English language to a language widely spoken in the Indian sociocultural context is what promoted it to a lingua franca in a multilingual India (Ramanathan, 2008).

\section{A Policy Experiment that Backfired}

As each Indian State was adapting and implementing the mTLF in its own way, the state of West Bengal ordained its own state education policy in 1982 that removed the English language from its primary school system and instead replaced it with Bangla, the native language (Acharya, 1982). The substitution was followed by "major interventions in Bangla language-teaching" (Sen, 2015, p. 269). People who supported the policy argued that Bangla language use will make school more appealing to poor and rural learners and thus increase the recruitment, retention, and graduation/completion rates which would help improve the literacy percentage of the state of West Bengal (Chakrabortya \& Bakshic, 2015). They believed that the policy would be instrumental in improving the quality of living and thus promote equality by making education accessible to all. Twenty-four years later, in 2007, the state government decided "to reverse the decision and re-introduce English into primary schools" (Sen, 2015, p.269). Research literature on this policy suggests that several factors were responsible for the failure of the policy. Some significant ones include:

- No positive trends were observed in the recruitment, retention, and graduation/completion rates amongst the rural and urban population (Scrase, 2002).

- When the cohorts affected by the policy were compared with cohorts (with comparable levels of education and experience) from other Indian states where English was not abolished, "a 68\% reduction in wages" for those that were affected by the language policy was recorded, indicating "a remarkably high English skill premium in the labor market" (Chakrabortya \& Bakshic, 2015, p.1).

Interpreting the fate of the policy, it can be understood that upon graduation, the children from West Bengal who were not introduced to English in elementary school, because of the policy, now had to compete in the labor market (that spans nationwide across India) with people from other Indian states who were not affected by the policy and so had English introduced to them in elementary school. The competition also existed instate because there were older workers who had English introduced to them in elementary school because they had started their schooling before the policy was implemented. Taken together, because of the English language's value in the labor market across India, denying English education to elementary school children was widening the rich-poor gap, rendering the language policy ineffective (since its original purpose was to remove inequality) (Chakrabortya \& Bakshic, 2015).

\section{English in India: Linguicism and Indian English}

English not only maintained its unusual and indispensable status within the Indian primary and secondary school system, it also made it all the way into higher education as well (Omidvar \& Ravindranath, 2017) and was being used across the nation to help meet the social, administrative, and literacy needs of the population (Devi, 2017). Moreover, knowledge of English provided nationwide mobility for Indian citizens (Shin, 2013). Somehow, 
the nation had unified under this one language and this allowed for socioeconomic progress (Pal, 2016). While the knowledge of a common language (English) was facilitating communication within the multilingual framework of India, it was also very useful for international trade as India opened its doors to globalization (Chakrabortya \& Bakshic, 2015).

English in a globalized India has now become essential not just in academia, but in other areas like popular media, pop and corporate culture, entertainment, and business, to name a few (Omidvar \& Ravindranath, 2017). Thus, English is enjoying a prestigious position within the multitude of Indian languages, and many educators and sociolinguists believe that English is disempowering local vernaculars languages, especially the ones that lack a script. For example, Krishnaswamy and Burde (1998) argued that English effaced the language traditions of the rural majority of India by constraining their speech within the public sphere. They wrote:

"Thus, English-education and print-capitalism created a new urban-class of Indians thereby culling out the rural masses, their oral traditions, and the Indian languages and their literature from the mainstream. It serves as a powerful tool which turns the vast majority into illiterates-into a 'silent majority' which is marginalized while the English-educated minority from the urban areas is centralized" (p. 67).

Krishnaswami and Burde's fears were not unfounded since English has and is dominating the public dialogue in India, rendering the native languages powerless. This peculiar relationship between English and the native languages of India could be labelled as 'linguicism.' Phillipson (2003) defines linguicism as "the structural and cultural inequalities that ensure the continued allocation of more material resources to English than to other languages and benefit those who are proficient in English" (p. 47). However, it must also be acknowledged that not all theorists present a negative view on the English language's place in an Indian's life. Although some view English as a foreign language that recolonizes native language, others see English as a peculiarly Indian language pointing to examples of how Indians use English and make it their own. For example, D’Souza (2001) writes, "To view English as a module is to see it as independent and self-contained, but English in India is neither, as it interacts both with the other local languages and with world Englishes to give a synthesis that is unique and Indian" (p. 148). These types of debates, concerning the "Indian-ness" of English have given rise to a new literacy, culture, and language education (LCLE) issue ${ }^{2}$ and raise the question of whether English language education in India should be treated as a foreign, second, or native language.

\section{Observations and Critical Remarks}

The English language as a lingua franca in a multilingual India seems to have currently settled the need for a national language for India because the wide acceptance of English has obviated the need for selecting an Indian language as a national language (Shin, 2013). The English language is now essentially a mandatory language all over India and Indian society in general perceives the language as an instrument for inclusiveness and progress (Devi, 2017). However, if the society's growing reliance on English is to be coped with in a meaningful way, schools around the country will need to establish a 'language across the curriculum' perspective and a strategy of multilingualism (Omidvar \& Ravindranath, 2017). Therefore, English language curriculum development is one major area ${ }^{3}$ that needs attention if the quality of education is to be upheld. To that effect, the National Council of Educational Research and Training (NCERT) occasionally responds to common problems that the Indian education system encounters by publishing a reference document called the National Curriculum Framework (NCF). In the most recent ${ }^{4} \mathrm{NCF}$, the document's authors state:

"The present NCF proposes five guiding principles for curriculum development: (i) connecting knowledge to life outside the school; (ii) ensuring that learning shifts away from rote methods; (iii) enriching the curriculum so that it goes beyond textbooks; (iv) making examinations more flexible and integrating them with classroom life; and (v) nurturing an overriding identity informed by caring concerns within the democratic polity of the country” (p. 7).

\footnotetext{
${ }^{2}$ This issue is beyond the scope of this paper but is introduced to show what a follow-up paper can discuss.

${ }^{3}$ There are several other areas like teacher education and training, English proficiency and preparedness, etc., but curriculum development is vital and fundamental to all other areas and so a 'major' issue worth considering.

${ }^{4}$ Retrieved November 01, 2017, from http://www.ncert.nic.in/rightside/links/pdf/framework/english/nf2005.pdf
} 
Since the NCF's suggestions are a direct response to common inherent problems that have been observed and recorded across public schools in India, it can be inferred that in many Indian classrooms the learning was observed to be disjointed from the lives of the learners and the structure was becoming over-dependent on rote learning with exams being inflexible and disconnected from the many identities of the participants. Most of these problems can be resolved using best practices from LCLE research literature. Here are our observations:

(i) "Connecting knowledge to life outside the school" We believe that the resolution to this rests on taking a sociocultural approach to literacy didactics. To that effect, we would urge that the various public schools across India investigate and utilize the home and community resources of their learners to then establish a two-way connection. A good starting point for this enterprise would be to replicate the successful experiment presented in the article "Funds of knowledge for teaching: Using a qualitative approach to connect homes and classrooms" by Moll, Amanti, Neff, and Gonzalez (1992). In the research article, Moll et al., conduct an ethnographic investigation by interacting with the family members of the children in an effort to gather information about the work and skill history of the family (that they refer to as 'Funds of Knowledge'), which they then use to inform their curriculum design. Their aim was to help bilingual students take the maximum advantage of their first language capabilities to overcome the limitations imposed by a restricted knowledge of the second language. We believe that when teachers and schools in India seek out and use the available funds of knowledge in their community they will be able to increase the likelihood of achieving genuine multilingual literacy while fostering a sense of community belonging and bestowing a more fertile education that connects knowledge and meaningmaking to the learner's life beyond the school's boundaries.

(ii) "Ensuring that learning shifts away from rote methods" We believe that one possible solution is to approach it from a social semiotic perspective. Given that most students in an Indian classroom are multilingual, a shift from a focus on language to a focus on mode will be very helpful. A good resource to find workable models to use and replicate from is the book "Multimodal pedagogies in diverse classrooms: Representation, rights and resources" authored by Pippa Stein (2008). The solutions presented in the book are from successful curriculum experiments in South African classrooms, which share similar cultural policies on language as India (Phillipson, 2003), and so can be easily reinterpreted for use in an Indian classroom. In her book, Stein "challenges the idea of the dominance of a single form of representation" and explores how "different knowledges and cultural forms can be represented through multiple forms of representation" by remixing the diverse forms to "create new forms, new meanings, and new possibilities for learning" (2008, p. 3). We strongly believe that incorporating the use of multimodality into the curriculum in schools across India will enable a shift from a memory-based pedagogy (that is over-reliant on language) to a one that enhances learners' creativity and rational thought, which in turn will serve to improve the quality of pedagogy across the nation.

(iii) "Enriching the curriculum so that it goes beyond textbooks" We believe that the solution rests on taking a "critical literacy" (CL) approach to curriculum design. Inspiration can be sought from the article "Critical literacy in teaching and research" by Hillary Janks (2013). Janks emphasizes that "critical literacy is about enabling children to read both the word and the world in relation to power, identity, differences and access to knowledge, skills, tools and resources" (p. 227). In many of the case studies that she discusses, she emphasizes that a reliance on scripted textbooks alone can limit critical literacy. She adds that "because texts are always positioned and positioning, it is impossible to give a neutral account of any case" (p. 231), and so an effective curriculum that aims to promote critical literacy should be enriched with opportunities for students to also critically analyze the textbooks. We firmly believe that designing a curriculum with a deep understanding of critical literacy will encourage reflective didactics and a cyclical nature to syllabus design that goes beyond decreed textbooks and meets the needs of the community while also minimizing unequal access.

(iv) "Making examinations more flexible and integrating them with classroom life" We believe that to address this issue, educators will have to embrace "multiliteracies" and "new literacy" pedagogy in the classroom. A common problem is that the current examinations' structure is congruous with traditional literacy practices in the classroom where the students are not engaged in multiliteracies (e.g. searching online for information etc.). Scholarly LCLE literature also recognizes this issue as current and common ${ }^{5}$. For example, sociolinguists that study high-stakes testing in education, Campano, Ghiso, and Welch (2016), report that there has been "less attention to the literate practices of members of different cultural and linguistic groups" (p.9). Even Stein

\footnotetext{
${ }^{5}$ A detailed discussion on current literature about this issue is available in Kiramba (2017).
} 
(2008), highlights that examinations need to be enhanced with "a multiliteracies pedagogy, and in so doing can encourage innovation and change” (p. 51). Janks (2013) also shares her observations in regard to classroombased examinations, saying that "there is clear evidence that children do not read for meaning and are unable to assume the role of a participant" (p. 235). If examinations are inflexible and nonintegrated with classroom life, they can adversely affect "the teacher's driving motivation or desire - an aspect of her subjectivity" (Moje \& Lewis, 2007, p. 35). Taken together, we believe that once new literacy practices and multiliteracies are adapted as part of the curriculum it will inevitably change the structure of examinations, rendering them flexible and integrative.

(v) "Nurturing an overriding identity informed by caring concerns within the democratic polity of the country" We believe that to adequately understand and tackle this issue, educators will have to rethink their curriculum within a critical cosmopolitan framework (CCF). A good resource to borrow ideas regarding the CCF is the article "Ontologies of place, creative meaning making and critical cosmopolitan education" by Margret Hawkins (2014). In her article, Hawkins talks about how looking at curriculum design and classroom composition through "ecological" models can be helpful because "these models tend to take into account the players in interactions, local contexts in which interactions occur, broader national discourses, ideologies and policies, as well as global factors" (Hawkins, 2013, p. 96). Two interesting ideas that can be found in the article include (1) using digital storytelling and sharing the stories with other schools in an effort to encourage students to become literate on global issues while at the same time maintaining focus on the local community, and (2) sharing 'a day in the life' to encourage the students to think about their own community while also building a local identity, and putting it into a digital story (thus engaging in technological literacy) and then sharing the story and viewing the story, allowing the students to make comparisons and experience new facets of life, thus building global connections. We firmly believe that CCF-inspired curriculum design will help Indian teachers "bridge perspectives between the ever-increasing global shifts and movements and situated human interactions through a theorization of the mediational nature of place” (Hawkins, 2013, p. 90).

\section{Conclusion}

In this opinion article, we have discussed the cultural policy of language in India and how it has resulted in an impasse in regard to determining and deciding upon a national language policy. We discussed how English language use in independent India was allowed with the understanding that it would be replaced with an Indian language once a consensus was reached regarding the national language of choice. As educators, policymakers and politicians debated about which of the Indian languages would be universally accepted as the national language, English use across the country elevated it to the status of a lingua franca. Moreover, English had also become integral and universally accepted across the country, making it an indispensable part of the system and the economy. Since avoiding English was not an option anymore, the Indian education system adapted a three language strategy that includes English language instruction along with Indian language instruction. We concluded our discussion of the language policy issue with recommendations for educators in India on how to utilize best practices from LCLE literature to improve and maintain the quality of education whilst operating within the confines of the three language strategy.

\section{References}

Acharya, P. (1992). Abolition of English at Primary Level in West Bengal. Economic and Political Weekly, 17(4), 124-128.

Ambedkar, B. R. (2017).Dr. Babasaheb Ambedkar: Writings and Speeches. Ministry of Social Justice \& Empowerment. New Delhi: Government of India.

Annamalai, E. (2004). Managing Multilingualism in India: Political and Linguistic Manifestations. University of Michigan: Sage Publications

Bhattacharya, U. (2017). Colonization and English ideologies in India: a language policy perspective. Language Policy, 16(1), 1-21.

Campano, G., Ghiso, M., \& B. Welch. (2016). Partnering with immigrant communities: Action through literacy. New 
York: Teachers College Press.

Chakrabortya, T. \& Bakshic, S. K., (2015). English language premium: Evidence from a policy experiment in India. Economics of Education Review, 50, 1-16.

D’Souza, J. (2001). Contextualizing range and depth in Indian English. World Englishes, 20(2), 145-159.

Devi, S. (2017). Three Language Formula and the First and Second Language: A Case of North East India. Language in India, 17(8), 1-13.

Dua, H.R. (1993). The National Language and the ex-Colonial Language as Rivals: The Case of India. International Political Science Review, 14(3), 293-308.

Hawkins, M. R. (2014). Ontologies of place, creative meaning making and critical cosmopolitan education. Curriculum Inquiry, 44(1), 90-112.

Jayalakshmi, A. V. \& Kothari, R. G. (2017). Reflections on School Based Evaluation: Policy Perspectives and Researches. Educational Quest, suppl. Special Issue, 8, 209-221.

Janks, H. (2013). Critical literacy in teaching and research. Education Inquiry, 4(2), 225-242.

Kiramba, L.K.(2017). Multilingual Literacies: Invisible Representation of Literacy in a Rural Classroom. Journal of Adolescent \& Adult Literacy, doi: 10.1002/jaal.690

Kochhar, S.K. (2000). Pivotal Issues In Indian Education. New Delhi: Sterling.

Krishnaswamy, N. \& Burde, A. (1998). The Politics of Indians' English: Linguistic Colonialism and the Expanding English Empire. New Delhi: Oxford University Press.

Moje, E. B. \& Lewis, C. (2007). Examining Opportunities to Learn Literacy: The Role of Critical Sociocultural Literacy Research (pp. 15-48). P. Enciso \& E. B. Moje (Eds.). Mahwah, NJ: Lawrence Erlbaum Associates.

Moll, L. C., Amanti, C., Neff, D., \& Gonzalez, N. (1992). Funds of knowledge for teaching: Using a qualitative approach to connect homes and classrooms. Theory into Practice, 31(2), 132-141.

Omidvar, R. \& Ravindranath, B. K. (2017). Position of English in India: Three-way Categorization. Language in India, 17(5), 1-10.

Orman, J. (2008). Language Policy and Nation-Building in Post-Apartheid South Africa. Netherlands: Springer.

Pal, S. (2016). Demand and Changing Scenario of Higher Education. Journal of Socio-Educational \& Cultural Research, 2(4), 7-10.

Pattanayak, D.P. (Ed.).1990. Multilingualism in India. New Delhi: Orient Longman.

Phillipson, R. (2003). Linguistic Imperialism. Oxford: Oxford University Press.

Ramanathan, H. (2008). Testing of English in India: a developing concept. Language Testing, 25(1), 111-126.

Scrase, T.J. (2002). Globalisation and the cultural politics of educational change: The controversy over teaching of English in West Bengal. International Review of Education, 48(5), 361-375.

Sen, S. (2015). Abolishing English in schools: implications for higher education in West Bengal. Inter-Asia Cultural Studies, 16(2), 269-281.

Shin, S. J. (2013). Bilingualism in Schools and Society: Language, Identity, and Policy. New York: Routledge

Stein, P. (2008). Multimodal pedagogies in diverse classrooms: Representation, rights and resources. New York: Routledge/Taylor \& Francis. 